Article

\title{
Regime Confluence in Automobile Industry Transformation: Boundary Dissolution and Network Reintegration via CASE Vehicles
}

\author{
Liqiao Wang * and Peter Wells * \\ Business School, Cardiff University, Cardiff CF10 3EU, UK \\ * Correspondence: WangL45@Cardiff.ac.uk (L.W.); WellsPE@Cardiff.ac.uk (P.W.); \\ Tel.: +44-(0)7922067183 (L.W.); +44-(0)7809696062 (P.W.)
}

check for updates

Citation: Wang, L.; Wells, P. Regime Confluence in Automobile Industry Transformation: Boundary Dissolution and Network Reintegration via CASE Vehicles. Energies 2021, 14, 1116. https:// doi.org/10.3390/en14041116

Academic Editor: Lucrezia Songini

Received: 10 January 2021

Accepted: 17 February 2021

Published: 20 February 2021

Publisher's Note: MDPI stays neutral with regard to jurisdictional claims in published maps and institutional affiliations.

Copyright: (c) 2021 by the authors. Licensee MDPI, Basel, Switzerland. This article is an open access article distributed under the terms and conditions of the Creative Commons Attribution (CC BY) license (https:/ / creativecommons.org/licenses/by/ $4.0 /)$.
Abstract: Technological innovations in sociotechnical transitions are usually found in market or spatial niches. These novel niches may sometimes emerge and expand, and eventually may erode an established sociotechnical system regime. In this paper, we redefined niche emergence as potentially consequent from the convergence of different regimes. That is, it is proposed that innovative niches may be grounded in established regimes but subsequently expand or bridge to previously distinct and separate other sociotechnical system regimes. However, the extension of overlapping regimes creates new forms of "external" competition for industrial participants inside each regime. This paper therefore proposes that regime-regime confluence may be observed in (1) the boundaries between regimes potentially being broken via emergent new niches; (2) pre-existing local networks being fragmented and reformed into exclusive and/or wider networks; and (3) competitive challenges and pressures arising both from inside and outside the traditional industry. These outcomes are illustrated in this paper with the case of automobility transitions arising from the combination of C (connected), A (autonomous), S (shared), and E (electric) cars. The paper presents an analysis of 340 instances of regime-regime boundary crossing examples over 10 years of data drawn from specialist industry journals and websites. The number and diversity of the validated results show that CASE vehicles are both a cause and consequence of automobile industry transition, and hence that regime-regime confluence is an important neglected source of innovation and structural change.

Keywords: automobility; regime confluence; CASE; sociotechnical transition; innovation; industry boundaries

\section{Introduction}

The concept of a "niche" initially derives from studies of ecological distributions of species that featured "structural and instinctive limitations" and "exceedingly slow modification down through time" [1]. The natural sciences perspective thus gives two basic ideas. First, that the space available for niche growth is restricted. Second, that the pace of growth is sluggish. In sociotechnical transitions theory, these concepts are part of an evolutionary perspective in which a technological niche is embedded with the same meaning that a novel technology emerges in a confined (spatial or market) space, and it grows slowly if at all. Theoretically, new innovations are thus defined at the "niche" level [2-5]. In contrast, regimes represent well-established technologies with sizable markets, norms, rules, and restrictions. There are also clear boundaries between regimes, which each demonstrate independent dynamic stability. Boundaries between regimes are defined or determined by multiple characteristics, some of which are historical convention or social practice. Hence the boundary of a regime will have product or service characteristics: it is a car, or it is a loaf of bread. It will have societal needs characteristics: it serves mobility, or it serves nutrition. It will have ownership and managerial characteristics, regulatory characteristics, and definitions within, e.g., official data collection. Regimes 
will require distinct skills, at least some of which will be unique to the regime. Niche emergence may challenge the established regimes such that original norms and order may be broken and replaced by novel niches [6]. Geels argues that niche innovations may have distinct new performance attributes that, while disadvantaged in some regards (such as cost) are sufficiently attractive to warrant increasing penetration in markets. In parallel, an existing regime may be under destabilization because of, for example, changes in external conditions, which accelerate the opening of a "space" for niche expansion [7]. A new set of norms, rules, and relations between original regime actors and "new niches" will reach a state of new balance of dynamically-stable relationships [3,8,9]. There is much research on niche-regime interactions demonstrated in prior studies $[4,10,11]$. However, innovative niche emergence from regime-regime confluence has rarely been studied [12-14].

In this study, we propose that the future components of transportation in the form of connectivity, autonomy, sharing, and electrification (CASE) niche innovation in cars (the study does not include buses, commercial vehicles, or other transport modes) could both compel and facilitate regime-regime confluence. The reason to adopt CASE features is that (1) these elements come to contribute to environment sustainability through transformation of users attitudes and travelling modes along with underlying technology advances and (2) the popular emergence of the CASE concept components at around the same time 2008 [9]. Additionally, CASE concepts are all in the niche level $[8,15]$ nonetheless they have become highly developed. Niches are often carefully protected and shielded in incubation spaces, for example via government policy $[3,16]$ but they also could be competitive [17]. CASE elements could be combined as one because they are potentially interactive and mutually supportive. CASE concepts aim to change the commercial proposition from the physical entity alone (the automobile) to a multidimensional service-added tool. It is a fundamental challenge to automobility culture and to the established industry, but is also a profound opportunity.

CASE technologies also carry profound implications for energy use in automobility. Each individual element has the potential to improve fuel efficiency and reduce carbon emissions. Much effort is going into the optimisation of elements of CASE or the totality of the transportation system within which these vehicles may operate [18-23]. The applications have significant implications for traffic management, electricity supply, urban infrastructure use, fleet management, and many other features-enabled by the availability of real-time data [24]. This research has led to strong claims for the benefits of the CASE concept. For example, Jones and Leibowicz [25] claim that operational efficiencies with shared autonomous vehicles would mean that even if the vehicle miles travelled (VMT) were double that of privately owned vehicles (POVs) the net effect would be to lower costs and carbon emissions.

Autonomous cars in principle can offer more efficient driving modes compared with human control, thereby saving energy per distance travelled. Connected cars can allow, for example, efficient "platooning" of vehicles or optimized searching for proximate charge points for electric vehicles. Car sharing has long been advanced as a means of improving vehicle utilization at reduced ownership, thereby cutting carbon [26], and it is particularly popular in European urban areas [27]. Meanwhile, electrification of the powertrain in cars brings immediate carbon reduction performance [28] and, more significantly, the opportunity to use interactions between the electricity supply grid and the car fleet to achieve mutual benefits such as off-peak charging, peak load "shaving", and reduced installed electricity generation capacity requirements via technologies such as "vehicle-togrid" (V2G) (see for example, [29,30]).

CASE cars will embody a significantly different share of materials in their construction and use, thereby having important implications for existing resources with a high degree of dependence upon the automotive sector (e.g., steel, petroleum, and lead). The shift to battery electric cars with a much higher level of on-board electronics will create growing demand for materials such as copper, cobalt, nickel, and aluminium [31]. 
In combination, CASE technologies could ultimately result in fewer car sales per annum, particularly if sharing becomes established. Fewer cars will be removed from the roads because of crashes, while battery electric systems are expected to be more reliable and durable than petrol or diesel, reducing the need for replacement cars. There is a strong interest in making cars, and especially battery packs, part of nascent "circular economy" concepts, in part because of the high value of the materials involved [32]. Some forecasts suggest that circularity in this sense could be achieved in mature markets by 2050 [33].

This study contributes to the literature on sociotechnical niche expansion and the automotive industry by linking the CASE concepts as the individual and collective causes and consequences of sociotechnical transition. This study highlights the catalysing role of the technological niches comprising CASE to (1) help dissolve the boundaries between the relevant industries; (2) stimulate the transformation from a (product centric) automotive industry to a (service centric) automobilities industry; and (3) to be emergent as a property of regime confluence.

Section 2 provides an overview of the theoretical framing of the research, grounded in sociotechnical transitions theory and the concept of regime-regime confluence. As is explained in this section, the analytical focus is on the automotive regime, but the boundary crossing or dissolution activities are across more than one additional regime. Section 3 explains the methodological approach, where an innovative "real time" accumulation of data was adopted. In Section 4 the main empirical and narrative content of the paper is described. Finally, Section 5 presents the conclusions from the research. It is argued that a focus on regime-regime confluence has significant potential in seeking to explain medium-term sociotechnical transitions, and that the automotive industry provides a good illustration of this contention. More generally, the scope for future research is also highlighted. Theoretically, the concept of regime-regime interactions could be further elaborated to understand more clearly the nature of boundaries and the means by which they may be crossed.

\section{Sociotechnical Transitions and Regime Confluence in the Automotive Industry on Pathway to a Service-Centric Automobility Industry}

\subsection{The Automotive SocioTechnical System}

A sociotechnical system is often conceived as embedded in three levels: landscape, sociotechnical regime, and technological novelties or niches, which collectively can be understood as a long-term stable structure. The structure of the sociotechnical system is defined by the core or foundational technology (in this case, the car), and by the resultant industry (in this case the automotive industry), which together from the basis of deeply embedded social practice (in this case, automobility). The automotive system is one that can be identified as an individual sociotechnical system as it has these characteristics. The interconnections in and beyond the automotive industry and automobility are managed in this paper using the approach pioneered by Vayda [34] in a form of "progressive contextualization". Precisely because the core technology of the car, the structure of the industry, and the social practice of automobility are potentially in profound transition it is necessary to be "inclusive" in how the sociotechnical system and the transition process is defined.

The automotive industry has partly been guided by emergent policies from governments over a hundred years. The resulting automotive sociotechnical system has been largely stable, showing incremental innovation driven by road safety requirements [35,36], emissions regulation, and the governance of markets. Vehicle manufacturer have generally avoided engaging in the provision of service-centric aspects of automobility. Other regulatory and governance controls emerged over the production systems, capital-labour relations, state aid, and competitive pressures in the market. The cultural dimensions of automobility have been expressed and gradually informed by books, movies, fans and enthusiast clubs, songs and peripherical products, and is demonstrated in museums. Cars became a representative of a person's social status. Even more, automobility cultures around specific car manufacturers emerges as part of the industrial history of a country or 
region [37-39]. Correspondingly, it is highly relevant to daily lives so that the best-selling models in each country have traditionally symbolized the national character. Rules and regulations were therefore varied by country. Owing to the specific requirements in each country, cars were manufactured and adjusted to coincide with local context. This may drive different niche innovations in particular countries at different times. Institutionalization creates economic and social interdependencies that help stabilize the system [40]. Over time, this pattern of "national" industries and cultures has given way to international structures, driven by economies of scale and the increasing global alignment of regulations.

The automotive industry acts as one of the pillar industries in some countries such as Germany [41]. The large automotive companies involve the national economy by virtue of huge revenue incomes, by job creation and the support of companies in the supply chain and adjacent industries such as insurance. Cars are also a significant contributor to national environmental performance, especially by their emission contributions [42,43]. The automotive sociotechnical system has expanded dependences around key activities such as with commuting and travelling behaviours, which in turn reinforce the significance of the industry and its products [44]. The sociotechnical regime can be expanded from various perspectives $[45,46]$, particularly niche emergence. Thus, the whole transport system could be described as a large sociotechnical system [47], or macroscopically an automobile could also be a small sociotechnical system [40,48].

The automobility sociotechnical system is a "self-reproducing or autopoietic" system [49]. In the automobility system, the core product technology is the car, but also the added value services and functionality of automobility are fundamental to the regime. It is the transformation from the provision of tangible products to intangible services [50] that is currently underway for vehicle manufacturers and others in the automotive industry. Services that are digitalized that could form a new "data-driven culture" [51]. These services are added by platforms or agencies, which take advantage of the products made by car manufacturers, i.e., Uber. Platforms do not own assets but gaining profitability through their application as intermediaries between those that own cars and those that want to drive one or be driven to destinations. It can be seen that a mobility services market is a space that has not been widely exploited, compared with being a traditional car maker where the market is almost saturated [27,52-54]. Niche automobility service markets thus could be generated by traditional car makers through existing regimes or self-generated from the niche level itself, including by new entrants from other sociotechnical regimes. Niches are not devoid of competitive pressure, though they can sometimes be nurtured initially in protected spaces (e.g., via favourable government policy).

\subsection{Regimes in Sociotechnical Transitions}

Regimes have been defined in various ways. They have been categorized in the Geels model [55] as a broad "social" regime, "political" regime, or "technical regime". They can also be defined as more specific or narrow structures such as the "electricity regime", "natural gas regime", or "automobility regime" [4,56]. Regime convergence has accelerated over time with more interactions and complexity in between previously distinct regimes [56-58]. The intricacy of the regime surroundings enables sector interaction and communication not only between regimes but also within regimes. As a result, regime confluence enables niches innovation, niche emergence, and structural change via new alliances and networks $[8,12]$. The regime is supported by many substructures and nodes. Interactions between regimes can take various forms including: competition, symbiosis integration, and spill-over [57].

\subsection{Regime Confluence}

In this paper it is proposed that regime convergence is multidimensional, with implications both inside regime and on the periphery. The interior elements of regime interactions may be collaborative and/or competitive, as may the external elements [57]. Through the collaboration and cooperation of con-joint work, the relations between elements may 
become a network. A network refers to any system that shows the relations among members. This is the foundation of working together so that networks are one of the outcomes from regime confluence and coherence. In a stable sociotechnical regime networks will largely form inside the regime itself. However, in periods of change "pathways" of transition [59] may be instigated. It is proposed in this paper therefore that boundary-crossing regime-regime interactions may be enabled by network formation between companies.

Borrowing the conception of the multiactor network from Geels [6], Figure 1 shows the possibility of regime confluence and the role of business model innovation around the CASE concept of networks emerging. There are several regimes that were independent but are increasingly collaborative under the sociotechnical automotive system in which each regime defines the characteristics of its inside elements. The fringe of each regime could be modified regarding the dynamic movement and extension from the inside elements with other regimes. Therefore, the network relations both interior and exterior may vary over time. At present, little is understood in terms of the character of the boundary conditions for different sociotechnical regimes, and how those conditions might influence the transition process. There may be barriers at the boundaries that either enable or restrict confluence. Those barriers may be cultural, technical, economic, or regulatory for example. In this case, regime transition is triggered by the concept of CASE vehicle design, production, and deployment. Each participant in the new regime potentially contributes new elements that are drawn initially from the original regimes in question. It is worth remembering that the newly emergent regime should in time become dynamically stable as the members and the relations in the regime solidify, and as the general structure is kept from the initial conception.

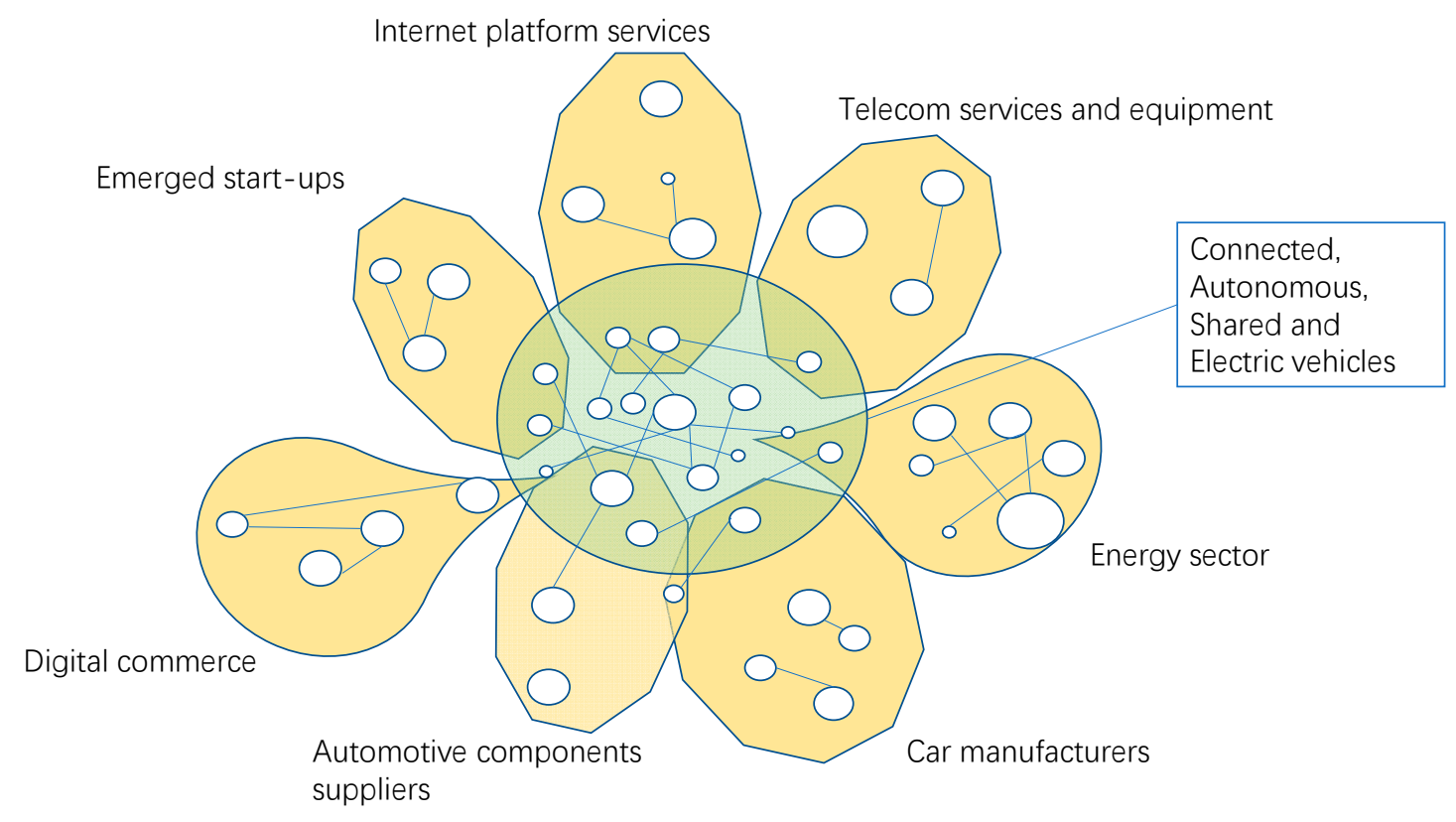

Figure 1. Regime confluence regarding new network emergence.

The research proposition is therefore that regime-regime confluence can be a significant source of innovation and sociotechnical transition. An observable phenomenon that would illustrate this anticipated convergence would be the development of networks and other corporate relationships (for example via mergers and acquisitions) across traditional regime boundaries. Section 3 below describes the research methodology to identify and quantify those trans-boundary relationships, while Section 4 describes the outcomes of the research. 


\section{Research Methodology}

In the research for this paper the approach is one of longitudinal immersion in the research domain, the automotive industry, underpinned by qualitative research methods [60]. Immersion in this sense involves multiple contact points with the research domain alongside iterations of reflexive interrogation. The active research in social contexts, via conferences, interviews, site visits, trade shows, and many other means, is primarily undertaken to provide contextual understanding. This discursive immersion process therefore entails engagement with policy makers, NGOs, regulators, industry representatives, lobbying groups, consultants, and other academics to create new knowledge [61,62]. In turn, the knowledge created informs the identification, selection, and use of the secondary information sources used in this paper.

Longitudinal immersion is here executed alongside qualitative research because this over-arching approach is suited to seeking to understand the emergent properties of innovation processes as they are mediated by society and the complexity of relationships within society [63]. Research into sociotechnical transitions often requires an exploratory, temporal, perspective to capture emergent social phenomena-for which qualitative research with document analysis is suited [64-66].

Two broad classes of documents were used in the research. First, the research sought to identify documents from those engaged in promoting or disputing CASE technologies for the automotive industry. Rather than seeking the details of the technologies concerned, our interest was to understand the presentation of the technologies by the proponents and critics, via press and media statements, position papers, and publicly available reports. The research does not, therefore, report on the success or otherwise of the relationships identified. It is entirely possible using these sources that a story turns out to be more speculation than fact, or that initial hopes failed to materialize. What this approach does capture, however, is the temporal dynamic of corporate interest in boundary crossing. The methodology flow shows as Figure 2.

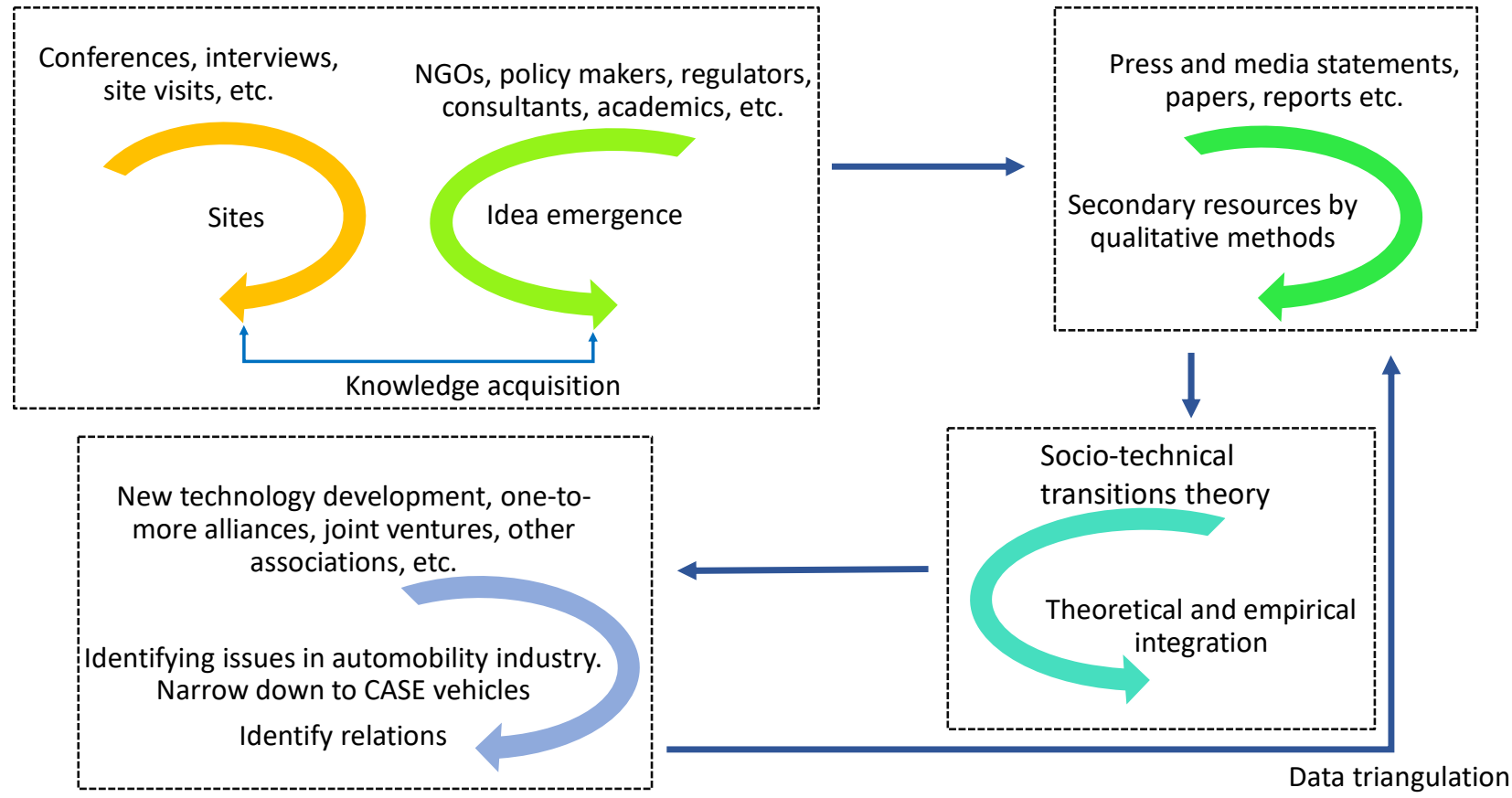

Figure 2. Research method flow.

This research adopts an unusual methodology is using "real time" news from specialist media to form the core of the data collection. Research in this manner is an unpredictable, long-term project. News features have stories that are of short, concise, fresh, and dynamic, in which it is easy to capture the events and link them to the general framework for the 
study. News stories were obtained from various websites, notably specialist websites such as Automotive News, BBC News, uk.reuters.com, electrive.com, electrek.co, economist.com, and IEEE spectrum. The reliability of these news was iteratively investigated by comparing with other mainstream sources. This process enabled triangulation of the data and thereby enhanced validity in the findings. Furthermore, hundreds of cases were collected, which would be impossible when using primary data collection methods. The reinterpretation of collected secondary data via flexibility gives a subjective meaning to the case and assists in theorization. There are risks of bias and coverage in these sources, which were primarily in the English language. It is likely that events in, for example, Japan, India, or China are somewhat under-represented. Nonetheless, the overall picture remains valid.

The car manufacturers' relations around autonomous, connected, shared, and electric vehicles were gathered from July 2009 to July 2019. In this time period, 340 cases were identified. The types of relationship recorded ranged from one-to-one cooperation in, e.g., new technology development, one-to-more alliances, equity joint ventures, and other associations between consortia members. Care was taken to avoid simple "double counting" of cases, but where an existing case was recorded as having a significant new development. July 2019 is the time node to end the data collection as (1) a dynamic research, cases could be added over time endlessly but defined stop point is needed for data calculation and evaluation to draw the results; (2) ten years' data is enough to draw a possible conclusion; and (3) the most important point is that there seems to be a decelerating trend of those relations from 2019, with the most alliances and cooperative relations established in 2017 and 2018. Thus, as the number of cases declined, we selected the end of July of 2019 as an ending point. New cases are still going on after July 2019, but they were not included in the research results. This "wave" of cases is an interesting first finding from the research, for it suggests that there was a historic moment or period of time when the automotive industry needed to build bridges with other sectors in order to understand and exploit key new technologies, and possibly to defend the market space against potential new entrants or the alliances formed by rival vehicle manufacturers (see $[67,68])$.

The CASE vehicles were the focal point to collect data and gather relationships. We started with automotive manufacturers and their partners who initially sought autonomous vehicle development, and the relations were simply "one to one", which is a car company plus another company. However, it was realized as the research progressed that collaborations involved in autonomous vehicle competition and development were not always centred on by car manufacturers. There were many "outsiders" who also established relations with other "outsiders", which did not involve the car makers at all. For example, Huawei as a telecommunication company also wants to build autonomous vehicles itself. The original Google autonomous vehicle was designed and built without help from a vehicle manufacturer. Automotive manufacturers are not mandatory in a partnership to make an autonomous vehicles, but could rather be a "vehicle supplier" to test and carry the newest functions. Therefore, the research strategy changed to cover all players who planned to build CASE vehicles, especially in 2018 and 2019. However, still, the aim was to focus the analysis on the vehicle manufacturers.

In this study 340 cases were identified, in which in the period 2009-2015 there was only 15 cases. Detailed data are shown monthly between 2016 and 2019 (July) in Figure 3 as the numbers before 2016 are too small to display in the same chart. Hence, there was a surge in cases during the period 2016-2019. In 201660 new cases were identified, 2017 had 112, 2018 had 100, and 2019 until July had 51. Relationships in the cases are not all newly formed. As noted above, in some cases there are instances that develop on a previous relationship. As we see from Figure 3, the cases in these four show a steady cumulative growth. Every month, at least one new case was facilitated by two companies to enhance autonomous and other CASE technology. 


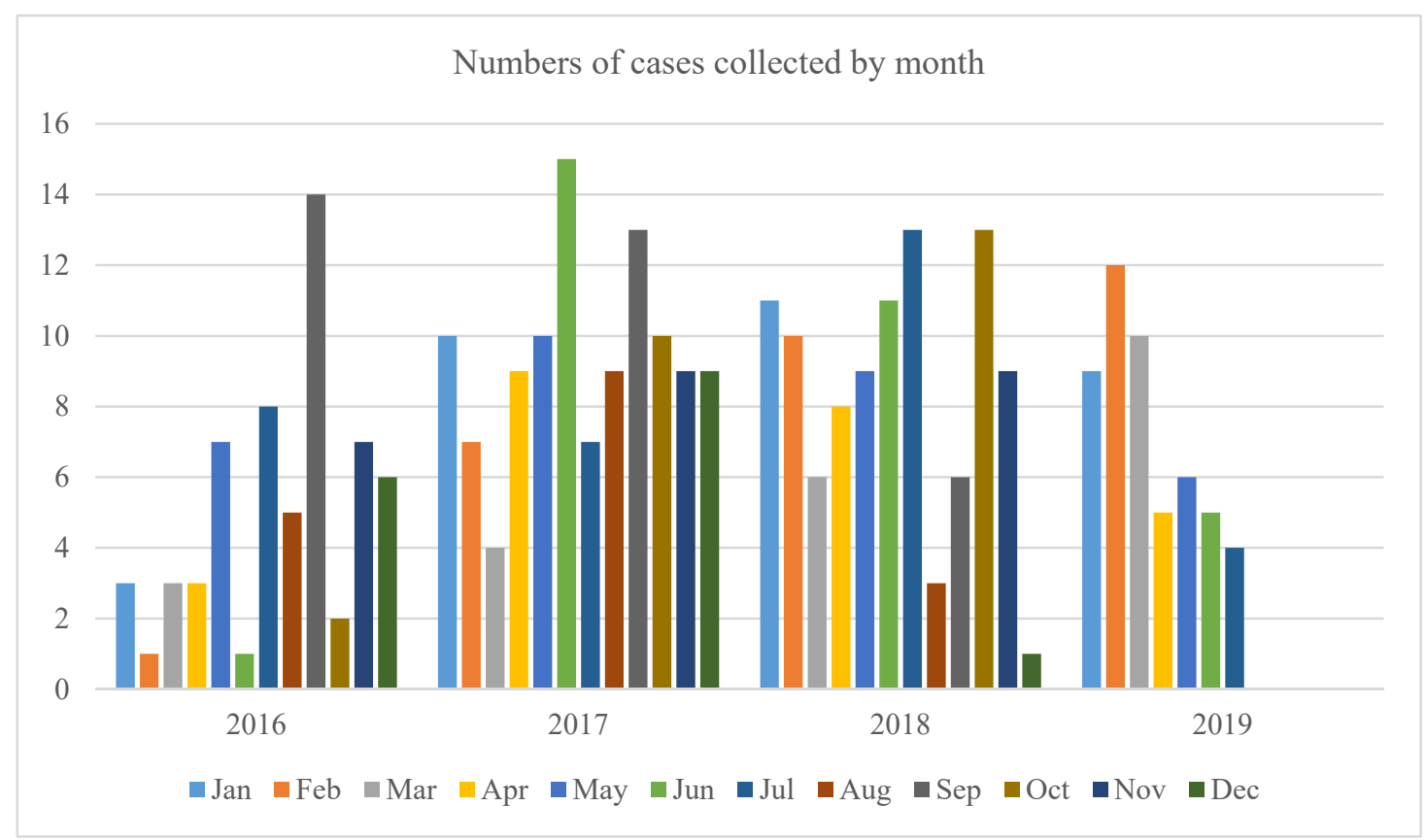

Figure 3. Numbers of cases collected per month.

Secondary data gives a general skeleton of how transitions occur and transform under a context of automobile industry to a service-centric automobility industry. It offers a timeline of events, the types of company that attempted to participate in CASE vehicles, the car manufactures involved, the major companies and other parties outside the traditional automotive industry, and the outcomes to date.

\section{Automotive Industry Transformation}

\subsection{The Contradictions}

In the current stage, the automobility industry faces four pairs of contradictions. The first one is between classic economic growth and the environment. Even though the electric vehicle revolution addresses aspects of environmental deterioration and may enable technological innovation to stimulate economic growth, it is still the case that the market penetration of electric vehicle is far short of sustainability [69-71]. In terms of energy and carbon emissions it is clear that in virtually all countries the adoption of electric vehicles displacing traditional petrol or diesel is a positive contribution. However, the displacement of a global fleet of nearly 1 billion cars will itself generate significant environmental burdens in recycling and in the consumption of new resources, as noted in the introduction to this paper. In the longer time period, it is possible that the circular economy will contribute to resolving this contradiction.

The second dilemma is between the environmental issues and personal requirements. Vehicles are an integral part in our daily lives. The primary consideration for users to buy a vehicle therefore is not the environmental impact of its production and use, it is convenience and safety while achieving mobility. Manufacturers therefore seek to produce vehicles that reconcile the environmental requirements at the same time delivering as functionality. Electric vehicles ideally are environmentally friendly, affordable, and safe. However, to date their higher initial cost and inconvenience in use (e.g., with restricted range) make electric vehicles less attractive compared with conventional combustion engine powered vehicles. Government therefore plays a mediating role between the users and manufacturers to balance the users' requirements and environmental sacrifice. Growth in car sharing, possibly constrained by the COVID-19 pandemic, may ameliorate some of this contradiction, as may other forms of micromobility such as electric bicycles. 
The third contradiction is the emergent business opportunity that conflicts with the traditional business model in the automotive industry. The traditional business model is increasingly incompatible with fast-changing technology and customer demands for differentiation. It is indicative that new entrants such as NIO in China are adopting innovative battery swap propositions that resolve both rapid charging concerns and the ability to upgrade battery packs as the technology improves. This third contradiction pressures the traditional automotive providers to extend their roles to be service valueadded suppliers to capture additional value. The customization of mobility thus is required. Drivers and passengers tend not to treat the vehicle just as a tool, but may also use vehicles as a relaxation space to chat and share experiences. For instance, Blablacar aims to create a relax atmosphere between drivers and sharers, or autonomous vehicles require more space for passengers and more functions of infotainment [27].

Last, the entry thresholds to be an automaker are lower owing to industry 4.0 smart digitalization, at least in terms of manufacturing. This results in a new contradiction between incumbents and new entrants. Many new entrants have been established in recent years (most famously Tesla) seeking to take advantage of lower barriers to entry. Technological development and environmental requirements necessitate that traditional vehicle manufacturers simplify production via common architectures and pay more attention to vehicle customization and connection. This complex system could not be completed by a single car company, it requires technologies from other partners. For example, to create an autonomous vehicle at least needs the support from a car company, a map company, a navigation company, a sensor company, and an information and communication company. The most important point is that the core of an autonomous vehicle is not the "vehicle" but its "autonomous" characteristics. The vehicle can be simplified to an electricity-powered system, but automation or sharing is far more complex. Therefore, companies in the CASE transition have an opportunity to step into the automotive industry and even to be an "automaker". The threshold of being an automaker is not as high as it used to be, but the competitiveness among all players is more severe.

\subsection{Competition Inside the Regime}

In principle, there should be a relationship between changes at the level of the sociotechnical system, and changes at the level of the constituent elements including the regime [72]. Incumbents can be important as sources of change; just as new entrants can be. Equally, incumbents may need to react to external (landscape) pressures and changes going on around them within and outside their sociotechnical system. That is, vehicle manufacturers will face the "normal" pressures of competition and market change within the automotive sociotechnical system. These normal pressures are significant because they act to restrict profitability in vehicle manufacturing and thereby give impetus to collaborative restructuring via mergers and acquisitions (M\&A), to constant efforts to increase productivity of capital and labour, and to the quest to expand markets in line with low-cost manufacturing locations.

The demand for new cars was strong and is still likely to be strong in future years. Sociotechnical transitions take decades to unfold across geographic, social, and economic space, so the traditional sale of cars as the main source of revenue may be expected to endure. In the years 2010-2018, an average of 70.6 million cars were sold globally. It is predicted that the global market may slightly reduce even in the period after the pandemic, but the basic demand of vehicles is expected to remain strong [73]. The big car manufacturers who dominate the whole industry as of 2019 were Volkswagen (12.2\% global market share), Toyota (11.4\%), and the Renault-Nissan alliance (10.9\%). Among them these groups took overall around 35\% market share of the light vehicle market [74]. The automotive industry is very competitive. General Motors was the world leader before 2010, however, Toyota took the position in 2020 from VW, and is the current market leader globally. Consolidation, such as the creation of Stellantis out of the merger of Fiat-Chrysler with PSA, is expected to continue inside the regime. 
Europe is the biggest car exporting region, accounting for around half of total global exports. Car export values in the European Union increased from \$126 billion in 1995 to $\$ 408$ billion in 2018 [75]. The EU is followed by North America and Asia, which each account for just less than a quarter of total global exports. Although the general pattern for each area is not much changed (in 1996 and 2017 respectively), the picture is more fragmented with more countries involved in the 20 years to 2020. Germany accounts for the single country share of exports with around $20 \%$ of in the world total, while Japan is the second largest car export country with $16.88 \%$ in 1996 and down to $13.71 \%$ in 2017. The third country was Canada in 1996, which took over $10 \%$ while in 2017, four countries were shared the third place with around the same figure ranged 5-6\% [75]. These locations thus become areas of vested interest in both the continuation of traditional automotive industry practice, but also in participation in the emergent transition to the newer practices embodied in CASE vehicles.

It is worth noticing that in 2019, the Renault-Nissan alliance took the third place [75]. The configuration of the alliance gave higher opportunities for market penetration across countries and cultures. It helps both manufacturers to understand the reciprocal markets to permeate quicker, also helps to share the data and technology to reduce the unit costs. However, the crisis with Ghosn also exposed the risks of such alliance structures. Other alliances attempts such as that between of FCA and PSA [76] show different risks, in this case with regulators concerned about a potential EU monopoly position on light vans, although the alliance eventually gained permission. The traditional M\&A has long been viewed as a method that allows a company to grow faster and stronger in a short time, but it is difficult to achieve all the synergies hoped for. This is a trend among big car companies, which are willing to extend their businesses in a short period such as Daimler acquired the car sharing platforms [77]. These acquisitions and mergers make company internationally involved by which the companies could fulfil the local market requirements with lower risk.

The new emergent alliances and acquisitions are international, often driven by developing countries, e.g., China and India. The similarity between these two countries is both demographic and economic. The potential large user market and capital investment give impetus to acquisition strategies. The typical examples are the Tata acquisition of JLR and Geely of Volvo. Over 20\% of Volvo sales are in Sweden, and EU is the largest sales region for Volvo, followed by China and the US [78,79]. The successful penetration by Volvo in the Chinese market may partially be due to Geely acquiring Volvo.

However, the automotive industry is not a "global" industry, it is still world regional in character. Toyota is one of the top selling companies, with $24.8 \%$ market shares in Japan while $30.6 \%$ in North America and 18.8\% in Asia [80]. Toyota is mostly produced in Japan and sold domestically but with a very small market share in the EU. Even within China, a local car company has many challenges to overcome (e.g., with policy barriers) when selling its products in another province, especially when they have local brands.

\subsection{The New Challenges to the Traditional Automobility Industry}

However, automotive manufacturers also face the "abnormal" challenges in transitioning to automobility from two sources. First, the fundamental innovative technologies call for the tremendous transformation of traditional automakers to develop new capabilities. To achieve this new form of automobility requires conventional automakers both strategically and practically to embrace these competencies. Second, the automobility transition involves many new entrants, which may compete against with traditional car makers, often with innovative business models and customer propositions that are not easily replicated.

When exploiting Industry 4.0, automotive manufacturers may try to turn their role from product providers to service suppliers, which require them to challenge and compete in areas where they never extended previously. In these areas, automotive manufacturers are not necessarily the dominant entities, they may be participants who play an auxiliary role. When a vehicle becomes a service tool, the feeling of involvement may be more 
important than the driving experience. To maximize the efficiency and pleasure of the experience, intelligent mapping, and navigation are essential and the extension of connection from phone-to-vehicle to vehicle-to-everything is inevitable. Be smart, be intelligent, and be selective are the central principles for a service tool. This is the new challenge to automotive industry to compete with the "native players" who are "native" in this area such as Ericsson and Bosch.

However, the autonomous vehicle contributes a unique and new arena to all potential market participants. To build this product is a challenge for all players because none of them have made it before and none of them could complete such a project exclusively. However, this race to bring a product to the market is unpredictable, and expensive. It was declared by the CEO of Transit, Sam Vermette: "New modes of mobility are entering the market at record speeds. It took decades for car-sharing to catch on. Now, e-bikes and scooters are being rolled out in weeks" [81].

The innovative niche market is even broader. E-scooters are easy, portable, and can be shared. In some degree, e-scooters are an extension of electric vehicles because they share similar networks to gain the user adoption [82]. It is the same principle for the electric bike niche market. Additionally, many alternatives to pure petrol or diesel cars are available or could be commercialized in the markets very soon. Toyota, for example, has deployed roof-mounted solar cells mixed with other power functions to extend the vehicle range and be totally clean without worry under any weather conditions [83].

Traditional car manufacturers tried to develop autonomous vehicles independently, but had to acknowledge that an autonomous vehicle is not merely another type of car, it requires higher coordination and cooperation with varied parties [84]. As BMW finally admitted, they need help from outsiders rather than to take all techniques and integrate in one [85]. Therefore, a successful transition is required for traditional carmakers. For example Toyota invested $\$ 500 \mathrm{~m}$ in Uber's driverless taxi program [86].

However, many respects the negative externalities of automobility are not new, they are just more intense than previously. They include (1) carbon emissions, decarbonization, and climate change, (2) road traffic deaths and injuries, (3) air quality, (4) noise, urbanization, and stress, (5) congestion and the environmental burdens of infrastructure, (6) the geopolitics of petroleum supply and demand, and (7) inevitable resource consumption.

From Table 1, we can see that the trajectory of CASE seems path dependent, it is somewhat coherent and will create further lock-in tendencies. None of the elements individually could fulfil all the requirements and tackle all the issues. Therefore, CASE in its idealized form is a comprehensive package to address concerns and derive maximum advantage from each element. In the automobility sociotechnical system, the automotive industry is the one still to play the essential role at the heart of integrating CASE technologies.

Under multipurpose actions (i.e., political, geographical, market, and environmental), CASE dissolves the boundaries between conventional automotive industry and many other industries, and meanwhile enables multilayer wider network crossing-bounded reintegration.

Table 1. Issues and benefits from CASE vehicles.

\begin{tabular}{|c|c|c|c|c|}
\hline & Connectivity & Autonomous & Shared & Electric \\
\hline Carbon emissions & $\begin{array}{l}\text { Fewer stop and starts } \\
\text { could decrease emissions }\end{array}$ & $\begin{array}{l}\text { Effective vehicle usage, on } \\
\text { average decrease the } \\
\text { emissions }\end{array}$ & $\begin{array}{l}\text { Should be lower if more } \\
\text { trips are shared }\end{array}$ & $\begin{array}{l}\text { Yes, lower or zero if } \\
\text { renewable electricity } \\
\text { sources used }\end{array}$ \\
\hline Road deaths and injuries & Yes, should be fewer & $\begin{array}{c}\text { Yes, properly executed } \\
\text { and designed autonomous } \\
\text { vehicles should reduce } \\
\text { crashes }\end{array}$ & $\begin{array}{c}\text { Fewer if fewer vehicles are } \\
\text { on the road and average } \\
\text { distances reduced }\end{array}$ & $\begin{array}{l}\text { No direct impact. May } \\
\text { increase crashes due to } \\
\text { low noise in operation }\end{array}$ \\
\hline Air quality & Indirectly improved & $\begin{array}{l}\text { Yes, vehicle efficient usage } \\
\text { could improve air quality }\end{array}$ & $\begin{array}{l}\text { Yes, if on-road numbers of } \\
\text { vehicles are reduced }\end{array}$ & $\begin{array}{c}\text { Yes, as they are zero } \\
\text { emissions at point of use }\end{array}$ \\
\hline
\end{tabular}


Table 1. Cont.

\begin{tabular}{|c|c|c|c|c|}
\hline & Connectivity & Autonomous & Shared & Electric \\
\hline Noise & Some marginal benefits & Some marginal benefits & $\begin{array}{l}\text { Yes, if on-road numbers of } \\
\text { vehicles are reduced }\end{array}$ & $\begin{array}{c}\text { Lower noise overall, } \\
\text { especially at low speed. } \\
\text { Mandated noise in many } \\
\text { urban settings }\end{array}$ \\
\hline Urbanization & $\begin{array}{c}\text { Could be more, expanded } \\
\text { to rural areas }\end{array}$ & $\begin{array}{l}\text { More difficult to achieve } \\
\text { in a complex urban } \\
\text { environment }\end{array}$ & $\begin{array}{l}\text { Often deployed in urban } \\
\text { areas to release parking } \\
\text { spaces }\end{array}$ & $\begin{array}{l}\text { Currently mainly urban } \\
\text { usage due to range anxiety }\end{array}$ \\
\hline Congestion & $\begin{array}{l}\text { Reduces the stress of } \\
\text { congested traffic on } \\
\text { drivers and occupants. } \\
\text { Smart traffic } \\
\text { managements may reduce } \\
\text { congestion }\end{array}$ & $\begin{array}{l}\text { Reduces the stress of } \\
\text { congested traffic on divers } \\
\text { and occupants }\end{array}$ & $\begin{array}{c}\text { Should reduce congestion } \\
\text { in urban areas }\end{array}$ & $\begin{array}{c}\text { No direct influence on } \\
\text { congestion }\end{array}$ \\
\hline $\begin{array}{l}\text { Environmental burdens of } \\
\text { infrastructure }\end{array}$ & $\begin{array}{c}\text { Yes, needs more } \\
\text { communications } \\
\text { infrastructure, e.g., } 5 \mathrm{G} \\
\text { networks }\end{array}$ & Yes, needs even more & $\begin{array}{l}\text { No significant added } \\
\text { burden }\end{array}$ & $\begin{array}{l}\text { Yes, charging stations } \\
\text { required. Old fuel stations } \\
\text { need to be } \\
\text { decommissioned }\end{array}$ \\
\hline $\begin{array}{l}\text { Geo-politics of fuel and } \\
\text { materials supply and } \\
\text { demand }\end{array}$ & No direct significant issue. & No direct significant issues & No direct significant issues & $\begin{array}{l}\text { Independence from } \\
\text { geo-politics of petroleum, } \\
\text { new dependencies on e.g., } \\
\text { rare earth; cobalt }\end{array}$ \\
\hline Resource consumption & $\begin{array}{l}\text { Yes, rare metals inside of } \\
\text { sensors and other parts, } \\
\text { and infrastructure }\end{array}$ & $\begin{array}{l}\text { Yes, rare metals inside of } \\
\text { sensors and other parts }\end{array}$ & No direct significant issues & $\begin{array}{l}\text { Yes, a large amount of } \\
\text { copper, lithium and other } \\
\text { materials required }\end{array}$ \\
\hline
\end{tabular}

\subsection{The Dissolution of Industry Boundaries}

The terminology of "industry" clearly draws a boundary for products and companies to identify which categories they belong to. Each industry has norms to evaluate the performance for all participants if they fulfil the requirements. The industry is constructed as a stable structure with dominant core players and auxiliary participants. The position of each element within an industry is varied by the definition of this industry. The automotive industry, for instance, is an automaker-dominated field, in which parts suppliers are playing a supplementary role.

The transition gives an opportunity to those new entrants, which own applicable technologies, capabilities, or concepts to invade into the current automotive system, to substitute and even to subvert the stable but dynamic whole. In terms of such a new transformation from the automotive (product) industry to automobility (service) industry, it is not yet entirely evident where the boundaries of the new sociotechnical regime will be formed, and which companies will come to dominate the regime. The outcomes will be contested and emerge as a product of the actions from companies, governments, consumes, regulators, and others. The service platforms offer another capability of automobility while car makers could be more than a product provider. It is the same for the technologically intensive sectors in which "tech-giants" could provide higher performance service attributes for vehicle. Therefore, the individual vehicle is not necessarily the focal point in CASE technology. The thresholds of being an automobility manufacturer therefore are lower for information technology giants and service providers. Successful entry to this emergent market is not guaranteed. For instance, the UK appliance manufacturer Dyson announced a plan to build electric vehicles, while later they abandoned their plan to enter the EV segments [87]. Again, this suggests that outcomes are not readily predictable.

However, for either service-supplier, innovative technology creator, or traditional car makers, this emergent automobility arena could be said to be "new" to all players. In other words, the thresholds are the same for all players as each of them holds part of the capabilities needed to succeed. Of course, each player comes with a distinct set of assets and competences that may enable or restrict their ability to participate in the future automobility. 
To create new portfolios, traditional vehicle manufacturing will face two-extreme tensions between the standard competitiveness. They may be vertically and horizontally integrated to those that used to be suppliers to diversify the supplementary range to irrelevant domains. The areas may extend to where they have never been or deepen to a field they may never have thought to enter, competitors or those that used to be opposite to this domain. "Collaboration-integration" is a strategy described by Pinkse [24]. However companies may lack an understanding of how to achieve this balance. New synergies in the new portfolios therefore are required [67]. The autonomous vehicles contribute as a bridge to switch automotive (product) to automobility (service) with the combination of electric, connected, and shared features to gradually dissolve industry boundaries.

Figure 4 from a diagrammatic view demonstrates cross-boundary relations over ten years for autonomous vehicles. Figure 4 did not include cross-boundary relationships for autonomous vehicles as such. Automotive companies with more cross-boundary relationships formed are revealed to be more central in the diagram, and in larger font. Some non-automotive companies also emerge as significant in this diagram, for Didichuxing, the biggest Chinese car sharing platform, NVIDIA the sensors supplier company, and Ericson the international telecoms company. Again, apart from the vehicle manufacturers, there are also several relations around CASE but without any car manufacture participating.

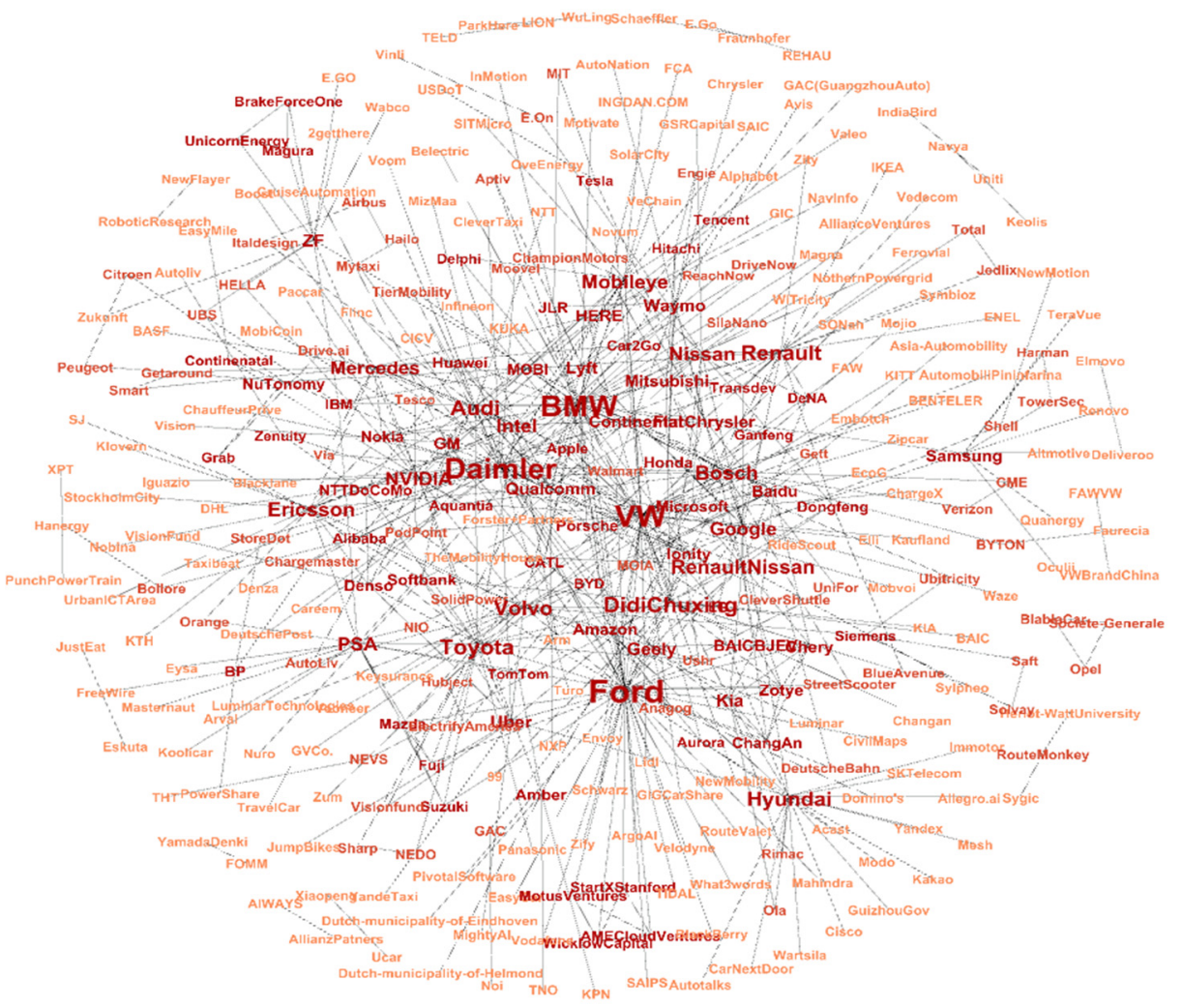

Figure 4. Automobility network to build an autonomous vehicle.

Boundary dissolution seems to inspire the latent possibility for new cooperation relationships and to extend the existing cooperation circles. From a vehicle functionality perspective, the car is thereby designed to maximize the service potential while improving the driving experience. The immergence of this network is a process of complexity for both users and industry participants [88]. The network portrayed here is coevolutionary with the process of industry boundary dissolution. Without boundaries, networks become bigger and wider, more powerful and influential. The network here has changed from a dot-to-dot network to network-to-network, it is thereby a mechanism to transfer from the original regime to a newly generated regime. 
4.5. CASE Accumulated the Network Transformation from the Automotive (Product) Industry to the Automobility (Service) Industry

The automobile industry has been systematically changed to consecutively adapt the innovative knowledge and incorporate it. Establishing alliances and sharing knowledge help traditional car makers improve their current states. Alliances are more possibly successful if they have absorptive ability and capability to accept new knowledge [44]. Since the boundaries have been broken and collaborative relations have accumulated, wider networks are gradually reintegrated to reconcile with the contextual conditions changing.

The automobility (service) industry has developed from a single organization-controlled supply chain to a multitier network, the system is dynamically stable but more complex due to the multipartnering change [89,90]. Not only is the manner of network integration changing, the goals of partnership are also varied compared with mass-market standardization because of tailored personalization. Alliances are transferring from production-based to service-oriented business strategy after 2000 and until now increased revenues are generated by value-added services. Physical products are measured by quality, and service can be measured by customer valuable feedback [50].

The traditional automotive industry, at least on the concept level, is in an advantageous position to combine CASE vehicles. The reasons include: (1) the four concepts are emerging roughly at the same time, around 2007-2009, (2) the automotive enterprises are capable of conjoining CASE in a one vehicle, and (3) they are cars. Transitions in traditional industry have challenged the concepts from "automobile" to "automobility" to "mobility as a service". The pattern thus is from "inclusive wider ICT companies" to "exclusive all possibilities" to embrace service platforms through mergers and acquisitions.

The network complexity in the automotive industry refers not just to the relationship network erection between spare parts suppliers, ICT companies, and automakers but also the service value network emerging between consumers and products. Further, as the additional proportion of participants are ICTs rather automakers, it results in the network inclination gradually towards to ICT based service value network [52].

\section{Conclusions}

Competition within an industry is often evidenced by technological or organizational innovation, and endeavours to show cost leadership or brand differentiation. However, sometimes an industry faces such a profound period of change that it is transformed. This transformation is understood to occur in conditions where the industry is at the heart of a sociotechnical system, forming a sociotechnical regime, where the system as a whole is undergoing transition.

The causes or impetus for sociotechnical transition may come from niche innovations that expand to displace an existing regime. This paper, however, demonstrates that transition can occur when a regime starts to impinge upon one or more previously distinct regimes. At the interface between or across regimes, the transition process is manifested by (among other things) intercorporate relationships being formed in order to bring together diverse capabilities and capacities as needed. The paper has used the CASE concept as a proxy for the requirement for boundary crossing. The analysis in this sense is centred on the existing automotive industry. Alternatively, if the research were focused on another domain such as "information and communication" then a related but different story could be told about how that particular sociotechnical regime is also crossing previously distinct boundaries including the automotive regime.

In consequence, the future energy consumption and emissions performance of the supply of automobility is no longer a matter simply of engine design and under the control of the automotive industry and its liquid fuel suppliers. The transition underway in the automotive regime is, as we have demonstrated here, taking the industry into engagement with a wide range of partnerships, which have the potential to influence energy consumption, energy carriers, and emissions. 
The outcome of these processes is not a foregone conclusion. This paper provided evidence of multiple partnerships being formed across regime boundaries, but has not sought to analyse whether or not those partnerships have been or will be successful. Further research is needed to establish the reasons for success or failure in the creation of new regimes out of this confluence process, and indeed the constituent character of the newly emerged regime once it achieves a degree of stability.

Further research is also needed on the nature of the boundaries. It is not clear yet how "permeable" regime boundaries are, as this is partly at least an empirical question. More clarity in the theorization of different boundary conditions could be a fruitful area of enquiry, including development of a perspective on how boundary conditions might be changed.

Author Contributions: Conceptualization, L.W. and P.W.; Methodology, L.W.; Writing-Original Draft Preparation, L.W.; Writing-Review and Editing, P.W. Both authors have read and agreed to the published version of the manuscript.

Funding: This research received no external funding.

Institutional Review Board Statement: Not applicable.

Informed Consent Statement: Not applicable.

Data Availability Statement: Publicly available datasets were analyzed in this study. This data can be found here: (autonew.com, bbc.co.uk, uk.reuters.com, electrive.com, electrek.co, economist.com, and spectrum.ieee.org).

Conflicts of Interest: The authors declare no conflict of interest.

\section{References}

1. Vandermeer, J.H. Niche Theory. Annu. Rev. Ecol. Syst. 1972, 3, 107-132. [CrossRef]

2. Kemp, R.; Schot, J.; Hoogma, R. Regime Shifts to Sustainability through Processes of Niche Formation: The Approach of Strategic Niche Management. Technol. Anal. Strateg. Manag. 1998, 10, 175-198. [CrossRef]

3. Geels, F.; Raven, R. Non-Linearity and Expectations in Niche-Development Trajectories: Ups and Downs in Dutch Biogas Development (1973-2003). Technol. Anal. Strateg. Manag. 2006, 18, 375-392. [CrossRef]

4. Dijk, M. A Socio-Technical Perspective on the Electrification of the Automobile: Niche and Regime Interaction. IJATM 2014, 14, 158. [CrossRef]

5. Schot, J.; Kanger, L. Deep Transitions: Emergence, Acceleration, Stabilization and Directionality. Res. Policy 2018, 47, 1045-1059. [CrossRef]

6. Geels, F.W. Technological Transitions as Evolutionary Reconfiguration Processes: A Multi-Level Perspective and a Case-Study. Res. Policy 2002, 31, 1257-1274. [CrossRef]

7. Geels, F.W. Socio-Technical Transitions to Sustainability: A Review of Criticisms and Elaborations of the Multi-Level Perspective. Curr. Opin. Environ. Sustain. 2019, 39, 187-201. [CrossRef]

8. Schot, J.; Hoogma, R.; Elzen, B. Strategies for Shifting Technological Systems: The Case of the Automobile System. Futures 1994, 26, 1060-1076. [CrossRef]

9. Khurshid, F.; Park, W.-Y.; Chan, F.T.S. The Impact of Competition on Vertical Integration: The Role of Technological Niche Width. Bus. Strategy Environ. 2020, 29, 789-800. [CrossRef]

10. Smith, A. Translating Sustainabilities between Green Niches and Socio-Technical Regimes. Technol. Anal. Strateg. Manag. 2010, 19, 427-450. [CrossRef]

11. Smink, M.; Negro, S.O.; Niesten, E.; Hekkert, M.P. How Mismatching Institutional Logics Hinder Niche-Regime Interaction and How Boundary Spanners Intervene. Technol. Forecast. Soc. Chang. 2015, 100, 225-237. [CrossRef]

12. Papachristos, G.; Sofianos, A.; Adamides, E. System Interactions in Socio-Technical Transitions: Extending the Multi-Level Perspective. Environ. Innov. Soc. Transit. 2013, 7, 53-69. [CrossRef]

13. Papachristos, G. Towards Multi-System Sociotechnical Transitions: Why Simulate. Technol. Anal. Strateg. Manag. 2014, 26, 1037-1055. [CrossRef]

14. Köhler, J.; Geels, F.W.; Kern, F.; Markard, J.; Onsongo, E.; Wieczorek, A.; Alkemade, F.; Avelino, F.; Bergek, A.; Boons, F.; et al. An Agenda for Sustainability Transitions Research: State of the Art and Future Directions. Environ. Innov. Soc. Transit. 2019, 31, 1-32. [CrossRef]

15. Ieromonachou, P.; Potter, S.; Enoch, M. Adapting Strategic Niche Management for Evaluating Radical Transport Policies--the Case of the Durham Road Access Charging Scheme. Int. J. Transp. Manag. 2004, 2, 75-87. [CrossRef] 
16. Verbong, G.; Geels, F.W.; Raven, R. Multi-Niche Analysis of Dynamics and Policies in Dutch Renewable Energy Innovation Journeys (1970-2006): Hype-Cycles, Closed Networks and Technology-Focused Learning. Technol. Anal. Strateg. Manag. 2008, 20, 555-573. [CrossRef]

17. Bakker, S.; van Lente, H.; Engels, R. Competition in a Technological Niche: The Cars of the Future. Technol. Anal. Strateg. Manag. 2012, 24, 421-434. [CrossRef]

18. Çalık, H.; Fortz, B. A Benders Decomposition Method for Locating Stations in a One-Way Electric Car Sharing System under Demand Uncertainty. Transp. Res. Part B Methodol. 2019, 125, 121-150. [CrossRef]

19. Carcangiu, S.; Fanni, A.; Montisci, A. Optimization of a Power Line Communication System to Manage Electric Vehicle Charging Stations in a Smart Grid. Energies 2019, 12, 1767. [CrossRef]

20. Cocca, M.; Giordano, D.; Mellia, M.; Vassio, L. Free Floating Electric Car Sharing Design: Data Driven Optimisation. Pervasive Mob. Comput. 2019, 55, 59-75. [CrossRef]

21. Folkestad, C.A.; Hansen, N.; Fagerholt, K.; Andersson, H.; Pantuso, G. Optimal Charging and Repositioning of Electric Vehicles in a Free-Floating Carsharing System. Comput. Oper. Res. 2020, 113, 104771. [CrossRef]

22. Liu, Z.; Miwa, T.; Zeng, W.; Bell, M.G.H.; Morikawa, T. Dynamic Shared Autonomous Taxi System Considering On-Time Arrival Reliability. Transp. Res. Part C Emerg. Technol. 2019, 103, 281-297. [CrossRef]

23. Mourad, A.; Puchinger, J.; Chu, C. A Survey of Models and Algorithms for Optimizing Shared Mobility. Transp. Res. Part B Methodol. 2019, 123, 323-346. [CrossRef]

24. Pinkse, J.; Bohnsack, R.; Kolk, A. The Role of Public and Private Protection in Disruptive Innovation: The Automotive Industry and the Emergence of Low-emission Vehicles. J. Prod. Innov. Manag. 2014, 31, 43-60. [CrossRef]

25. Jones, E.C.; Leibowicz, B.D. Contributions of Shared Autonomous Vehicles to Climate Change Mitigation. Transp. Res. Part D Transp. Environ. 2019, 72, 279-298. [CrossRef]

26. Arbib, J.; Seba, T. Rethinking Transportation 2020-2030. Available online: https:/ /www.rethinkx.com/transportation/ (accessed on 11 November 2018).

27. Wells, P.; Wang, X.; Wang, L.; Liu, H.; Orsato, R. More Friends than Foes? The Impact of Automobility-as-a-Service on the Incumbent Automotive Industry. Technol. Forecast. Soc. Chang. 2020, 154, 119975. [CrossRef]

28. Gómez Vilchez, J.J.; Jochem, P. Powertrain Technologies and Their Impact on Greenhouse Gas Emissions in Key Car Markets. Transp. Res. Part D Transp. Environ. 2020, 80, 102214. [CrossRef]

29. The Drive towards a Low-Carbon Grid: Unlocking the Value of Vehicle-Togrid Fleets in Great Britain. Available online: https://www.eonenergy.com/content/dam/eon-energy-com/Files/vehicle-to-grid/The\%20Drive $\% 20$ Towards $\% 20 \mathrm{~A} \% 20$ Low-Carbon\%20Grid\%20Whitepaper.pdf (accessed on 29 January 2021).

30. Xu, L.; Yilmaz, H.Ü.; Wang, Z.; Poganietz, W.-R.; Jochem, P. Greenhouse Gas Emissions of Electric Vehicles in Europe Considering Different Charging Strategies. Transp. Res. Part D Transp. Environ. 2020, 87, 102534. [CrossRef]

31. UNCTAD. Special Issue on Strategic Battery Raw Materials; United Nations: Gevena, Switzerland, 2019.

32. Canals Casals, L.; Barbero, M.; Corchero, C. Reused Second Life Batteries for Aggregated Demand Response Services. J. Clean. Prod. 2019, 212, 99-108. [CrossRef]

33. Kamran, M.; Raugei, M.; Hutchinson, A. A Dynamic Material Flow Analysis of Lithium-Ion Battery Metals for Electric Vehicles and Grid Storage in the UK: Assessing the Impact of Shared Mobility and End-of-Life Strategies. Resour. Conserv. Recycl. 2021, 167, 105412. [CrossRef]

34. Vayda, A.P. Progressive Contextualization: Methods for Research in Human Ecology. Hum. Ecol 1983, 11, 265-281. [CrossRef]

35. WHO. Road Safety Global Status Report on Road Safety (GSRRS). Available online: http://www.paho.org/hq/index.php? option=com_content\&view=article\&id=13434\&Itemid=42359\&lang=en (accessed on 24 November 2018).

36. NHTSA. Automated Vehicles for Safety. Available online: https://www.nhtsa.gov/technology-innovation/automated-vehiclessafety (accessed on 8 March 2018).

37. Cohen, M.J. The Future of Automobile Society: A Socio-Technical Transitions Perspective. Technol. Anal. Strateg. Manag. 2012, 24, 377-390. [CrossRef]

38. Geels, F.W.; Kemp, R.; Dudley, G.; Lyons, G. Automobility in Transition? A Socio-Technical Analysis of Sustainable Transport; Routledge Studies in Sustainability Transitions; Routledge: New York, NY, USA, 2012; ISBN 978-0-415-88505-8.

39. Wells, P.; Nieuwenhuis, P. Transition Failure: Understanding Continuity in the Automotive Industry. Technol. Forecast. Soc. Chang. 2012, 79, 1681-1692. [CrossRef]

40. Carolan, M.S. Ethanol's Most Recent Breakthrough in the United States: A Case of Socio-Technical Transition. Technol. Soc. 2010, 32, 65-71. [CrossRef]

41. Koptyug, E. Automobile Industry in Germany. Available online: https://www.statista.com/topics/3202/automobile-industryin-germany / (accessed on 14 May 2020).

42. Nieuwenhuis, P.A.H.F.; Wells, P. The Automotive Industry: A Guide; Centre for Automotive Industry Research: Cardiff, UK, 2001; ISBN 978-0-9525384-3-1.

43. Arnold, M. German Industry Hit by Biggest Downturn since 2009. Available online: https://www.ft.com/content/a1a14220-180 1-11ea-9ee4-11f260415385 (accessed on 14 May 2020).

44. Schulze, A.; Brojerdi, G.; Krogh, G. Those Who Know, Do. Those Who Understand, Teach. Disseminative Capability and Knowledge Transfer in the Automotive Industry. J. Prod. Innov. Manag. 2014, 31, 79-97. [CrossRef] 
45. Smith, A.; Raven, R. What Is Protective Space? Reconsidering Niches in Transitions to Sustainability. Res. Policy 2012, 41, 1025-1036. [CrossRef]

46. Bento, N.; Fontes, M. Spatial Diffusion and the Formation of a Technological Innovation System in the Receiving Country: The Case of Wind Energy in Portugal. Environ. Innov. Soc. Transit. 2015, 15, 158-179. [CrossRef]

47. Auvinen, H.; Tuominen, A. Future Transport Systems: Long-Term Visions and Socio-Technical Transitions. Eur. Transp. Res. Rev. 2014, 6, 343-354. [CrossRef]

48. Fraedrich, E.; Beiker, S.; Lenz, B. Transition Pathways to Fully Automated Driving and Its Implications for the Sociotechnical System of Automobility. Eur. J. Futures Res. 2015, 3, 11. [CrossRef]

49. Urry, J. The 'System' of Automobility. Theorycult. Soc. 2004, 21, 25-39. [CrossRef]

50. Godlevskaja, O.; van Iwaarden, J.; van der Wiele, T. Moving from Product-based to Service-based Business Strategies: Services Categorisation Schemes for the Automotive Industry. Int. J. Qual. Reliab. Manag. 2011, 28, 62-94. [CrossRef]

51. Dremel, C.; Herterich, M.; Wulf, J.; Spottke, B. Actualizing Affordances: A Socio-Technical Perspective on Big Data Analytics in the Automotive Sector. In Proceedings of the the 37th International Conference on Information Systems, Seoul, Korea, 13-15 December 2017.

52. Basole, R.C.; Rouse, W.B. Complexity of Service Value Networks: Conceptualization and Empirical Investigation. IBM Syst. J. 2008, 47, 53-70. [CrossRef]

53. Statista Uber's Users of Ride-Sharing Services Worldwide 2018. Available online: https:/ /www.statista.com/statistics/833743 /us-users-ride-sharing-services / (accessed on 10 January 2019).

54. Narayanan, S.; Chaniotakis, E.; Antoniou, C. Shared Autonomous Vehicle Services: A Comprehensive Review. Transp. Res. Part C Emerg. Technol. 2020, 111, 255-293. [CrossRef]

55. Geels, F. Technological Transitions and System Innovations: A Co-Evolutionary and Socio-Technical Analysis; Edward Elgar: Cheltenham, UK; Northampton, MA, USA, 2005; ISBN 978-1-84542-009-3.

56. Raven, R. Co-Evolution of Waste and Electricity Regimes: Multi-Regime Dynamics in the Netherlands (1969-2003). Energy Policy 2007, 35, 2197-2208. [CrossRef]

57. Raven, R.; Verbong, G. Multi-Regime Interactions in the Dutch Energy Sector: The Case of Combined Heat and Power Technologies in the Netherlands 1970-2000. Technol. Anal. Strateg. Manag. 2007, 19, 491-507. [CrossRef]

58. Budde, B.; Konrad, K. Tentative Governing of Fuel Cell Innovation in a Dynamic Network of Expectations. Res. Policy 2019, 48, 1098-1112. [CrossRef]

59. Geels, F.W.; Schot, J. Typology of Sociotechnical Transition Pathways. Res. Policy 2007, 36, 399-417. [CrossRef]

60. Wells, P.; Nieuwenhuis, P. Operationalizing Deep Structural Sustainability in Business: Longitudinal Immersion as Extensive Engaged Scholarship. Br. J. Manag. 2017, 28, 45-63. [CrossRef]

61. Robinson, S.; Kerr, R. Reflexive Conversations: Constructing Hermeneutic Designs for Qualitative Management Research. Br. J. Manag. 2015, 26, 777-790. [CrossRef]

62. Thorpe, R.; Eden, C.; Bessant, J.; Ellwood, P. Rigour, Relevance and Reward: Introducing the Knowledge Translation Value-Chain. Br. J. Manag. 2011, 22, 420-431. [CrossRef]

63. Eisenhardt, K.M.; Graebner, M.E. Theory Building from Cases: Opportunities and Challenges. AMJ 2007, 50, 25-32. [CrossRef]

64. Yin, R. Applications of Case Study Research; Sage: Thousand Oaks, CA, USA, 2002; pp. 1-192.

65. Corbin, J.; Strauss, A. Basics of Qualitative Research: Techniques and Procedures for Developing Grounded Theory, 3rd ed.; SAGE Publications, Inc.: Thousand Oaks, CA, USA, 2008; ISBN 978-1-4129-0644-9.

66. Wild, P.J.; McMahon, C.; Darlington, M.; Liu, S.; Culley, S. A Diary Study of Information Needs and Document Usage in the Engineering Domain. Des. Stud. 2010, 31, 46-73. [CrossRef]

67. Wells, P.; Wang, L. Borderless World 2.0. In Proceedings of the 30th International Electric Vehicle Symposium \& Exhibition, Stuttgart, Germany, 9-11 October 2017; pp. 1-10.

68. Wells, P.; Wang, L. Competitive Constellations as Boundary-Bridging in Socio-Technical Transitions: An Automotive Industry Case Study. In Proceedings of the 4th International Conference on New Business Models, Berlin, Germany, 1-3 July 2019.

69. International Energy Agency GEVO 2018. Available online: https: / / www.iea.org/gevo2018/ (accessed on 11 January 2019).

70. Rolander, N.; Stran, J.; Behrmann, E. The Dirt on Clean Electric Cars. Available online: https://www.bloomberg.com/news / articles / 2018-10-16/the-dirt-on-clean-electric-cars (accessed on 1 January 2019).

71. Stringer, D.; Buckland, K. Before the Electric Car Takes over, Someone Needs to Reinvent the Battery. Available online: https:/ / www.bloomberg.com/news/articles / 2019-01-06/before-the-electric-car-takes-over-someone-needs-to-reinvent-the-battery (accessed on 11 January 2019).

72. Bidmon, C.M.; Knab, S.F. The Three Roles of Business Models in Societal Transitions: New Linkages between Business Model and Transition Research. J. Clean. Prod. 2018, 178, 903-916. [CrossRef]

73. Statista Global Car Sales 1990-2020. Available online: https://www.statista.com/statistics/200002/international-car-sales-since1990/ (accessed on 3 June 2020).

74. Focus2move. World Car Group Ranking in the 2020. Available online: https://focus2move.com/world-car-group-ranking/ (accessed on 4 June 2020). 
75. HarvardGrwthLab. The Atlas of Economic Complexity by HarvardGrwthLab. Available online: https://atlas.cid.harvard.edu/ explore? country=undefined\&product $=1763 \&$ year $=2017 \&$ productClass $=$ HS\&target $=$ Product\&partner $=$ undefined\&startYear $=$ undefined (accessed on 13 March 2019).

76. Piovaccari, G.; Jewkes, S. FCA-PSA Deal Terms “set in Stone” for 50-50 Merger. Reuters, 20 May 2020.

77. Reader, R. Daimler Is Getting Cosy with Turo in a Bet on P2P Car Sharing. Available online: https://www.fastcompany.com/40 462006/daimler-is-getting-cozy-with-turo-in-a-bet-on-p2p-car-sharing (accessed on 19 October 2018).

78. BBC News Sweden's Best-Selling Car Not a Volvo. Available online: https:/ / www.bbc.com/news/business-38493295 (accessed on 4 June 2020).

79. Volvo. Volvo Cars Reports Best Ever First Half Year Sales in 2019. Available online: https://www.media.volvocars.com/global/ en-gb/media/pressreleases / 255019/volvo-cars-reports-best-ever-first-half-year-sales-in-2019 (accessed on 4 June 2020).

80. Toyota. Financial Data Shareholders \& Investors News. Available online: https://global.toyota/en/ir/finance/index.html (accessed on 15 February 2020).

81. Automotive News. Europe Renault-Nissan-Mitsubishi Investment Arm Takes Stake in Canadian Mobility. App. Available online: https: / / europe.autonews.com/article/20181105/COPY/311059947/renault-nissan-mitsubishi-investment-arm-takesstake-in-mobility-app?cciid=email-ane-daily (accessed on 7 February 2019).

82. Toll, M. Mopeds and Scooters Are Going Green-KYMCO Chairman Says Electric Scooters to Be Majority of New Model Sales. Available online: https:/ / electrek.co/2018/11/03/kymco-majority-electric-scooter/ (accessed on 7 February 2019).

83. Sensiba, J. Are Solar Vehicles Becoming Viable? Available online: https:/ / cleantechnica.com/2019/07/15/are-solar-vehiclesbecoming-viable/ (accessed on 18 July 2019).

84. Sigal, P. Why Tech Alliances Are More Crucial than Ever to Auto Companies' Survival. Available online: https: / / europe.autonews.com/article/20181202/ANE/181139995/why-alliances-are-more-crucial-than-ever-to-auto-companiessurvival?cciid=email-ane-daily (accessed on 7 February 2019).

85. Coppola, G. BMW in Talks with Automakers over Joining Its Self-Driving Group. Available online: https:/ / europe.autonews. com/article/20181204/ANE/181209896/bmw-in-talks-with-automakers-over-joining-its-self-driving-group (accessed on 7 February 2019).

86. BBC News. Toyota to Invest $\$ 500 \mathrm{~m}$ in Uber in Driverless Car Deal. Available online: https://www.bbc.co.uk/news/business-45 324753/ (accessed on 18 July 2019).

87. Dyson Automotive. See the Story behind the Dyson Electric Vehicle, Dyson Automotive. Available online: https://www.dyson. co.uk/automotive.html (accessed on 4 July 2020).

88. Amuzu-Sefordzi, B.; Martinus, K.; Tschakert, P.; Wills, R. Disruptive Innovations and Decentralized Renewable Energy Systems in Africa: A Socio-Technical Review. Energy Res. Soc. Sci. 2018, 46, 140-154. [CrossRef]

89. Mena, C.; Humphries, A.; Choi, T.Y. Toward a Theory of Multi-Tier Supply Chain Management. J. Supply Chain Manag. 2013, 49, 58-77. [CrossRef]

90. Elvers, D.; Song, C.H. R\&D Cooperation and Firm Performance-Evaluation of Partnering Strategies in the Automotive Industry. J. Financ. Econ. 2014, 2, 185-193. [CrossRef] 